\title{
The Impact of College Sports Success on the Quantity and Quality of Student Applications
}

\author{
Devin G. Pope* and Jaren C. Pope $\dagger$
}

\begin{abstract}
Empirical studies have produced mixed results on the relationship between a school's sports success and the quantity and quality of students that apply to the school. This study uses two unique data sets to shed additional light on the indirect benefits that sports success provides to NCAA Division I schools. Key findings include the following: (1) football and basketball success significantly increases the quantity of applications to a school, with estimates ranging from $2 \%$ to $8 \%$ for the top 20 football schools and the top 16 basketball schools each year, (2) private schools see increases in application rates after sports success that are two to four times higher than public schools, (3) the extra applications received are composed of both low and high SAT scoring students, thus providing potential for schools to improve their admission outcomes, and (4) schools appear to exploit these increases in applications by improving both the number and the quality of incoming students.
\end{abstract}

JEL Classification: D010, I230, J240

\section{Introduction}

Since the beginning of intercollegiate sports, the role of athletics within higher education has been a topic of heated debate. ${ }^{1}$ Whether to invest funds into building a new football stadium or to improve a school's library can cause major disagreements. Lately the debate has become especially contentious as a result of widely publicized scandals involving student athletes and coaches and because of the increasing amount of resources schools must invest to remain competitive in today's intercollegiate athletic environment. Congress has recently begun to question the National Collegiate Athletic Association's (NCAA) role in higher education and its tax-exempt status. Representative Bill Thomas asked the president of the NCAA, Dr. Myles Brand, in 2006: "How does playing major college football or men's basketball in a highly

* Department of Operations and Information Management, The Wharton School, Philadelphia, PA 19104, USA; E-mail dpope@wharton.upenn.edu.

$\dagger$ Department of Agricultural and Applied Economics (0401), Virginia Tech, Blacksburg, VA 24061, USA; E-mail jcpope@vt.edu; corresponding author.

We thank Christopher Bollinger and three anonymous referees for many useful comments and suggestions that significantly improved the manuscript. We also thank Jared Carbone, David Card, Charles Clotfelter, Stefano DellaVigna, Nick Kuminoff, Arden Pope, Matthew Rabin, John Siegfried, V. Kerry Smith, Wally Thurman, and Sarah Turner, as well as participants of the NBER's Higher Education Working Group and seminar participants and colleagues at U.C. Berkeley and N.C. State Universities. The standard disclaimer applies.

Received April 2007; accepted February 2008.

${ }^{1}$ For example, a history of the NCAA provided on the NCAA's official web site states, "The 1905 college football season produced 18 deaths and 149 serious injuries, leading those in higher education to question the game's place on their campuses" (http://www.ncaa.org/wps/portal). The 1905 season led to the establishment of the Intercollegiate Athletic Association of the United States (IAAUS), which eventually became the NCAA in 1910. 
commercialized, profit-seeking, entertainment environment further the educational purpose of your member institutions?"2

Some analysts would answer Representative Thomas's question by suggesting that sports does not further the academic objectives of higher education. They would argue that intercollegiate athletics is akin to an "arms race" because of the rank-dependent nature of sports, and that the money spent on athletic programs should be used to directly influence the academic mission of the school instead. However, others suggest that because schools receive a variety of indirect benefits generated by athletic programs, such as student body unity, increased student body diversity, increased alumni donations, and increased applications, athletics may act more as a complement to a school's academic mission than a substitute for it. Until recently, evidence for the indirect benefits of the exposure provided by successful athletic programs was based more on anecdote than empirical research. ${ }^{3}$ Early work by Coughlin and Erekson (1984) looked at athletics and contributions but also raised interesting questions about the role of athletics in higher education. Another seminal paper (McCormick and Tinsley 1987) hypothesized that schools with athletic success may receive more applications, thereby allowing the schools to be more selective in the quality of students they admit. They used data on average SAT scores and in-conference football winning percentages for 44 schools in "major" athletic conferences for the years 1981-1984 and found some evidence that football success can increase average incoming student quality. ${ }^{4}$ Subsequent research has further tested the increased applications (quantity effect) and increased selectivity (quality effect) hypotheses of McCormick and Tinsley but has produced mixed results. ${ }^{5}$ The inconsistent results in the literature are likely the product of (1) different indicators of athletic success, (2) a limited number of observations across time and across schools, which has typically necessitated a crosssectional analysis, and (3) different econometric specifications.

This study extends the literature on the indirect benefits of sports success by addressing some of the data limitations and methodological difficulties of previous work. To do this we constructed a comprehensive data set of school applications, SAT scores, control variables, and athletic success indicators. Our data set is a panel of all (approximately 330) NCAA Division I schools from 1983 to 2002. Our analysis uses plausible indicators for both football and basketball success, which are estimated jointly in a fixed effects framework. This allows a more comprehensive examination of the impact of sports success on the quantity and quality of incoming students. Using this identification strategy and data, we find evidence that both football and basketball success can have sizeable impacts on the number of applications

\footnotetext{
${ }^{2}$ Bill Thomas is a Republican congressman from California and previous chairman of the tax-writing House Ways and Means Committee. The full letter was printed in an article entitled "Congress' Letter to the NCAA" on October 5, 2006, in USA Today.

${ }^{3}$ A leading example of the anecdotal evidence has been dubbed "the Flutie effect," named after the Boston College quarterback Doug Flutie, whose exciting football play and subsequent winning of the Heisman Trophy in 1984 allegedly increased applications at Boston College by $30 \%$ the following year. Furthermore, Zimbalist (1999) notes that Northwestern University's applications jumped by 30\% after they played in the 1995 Rose Bowl, and George Washington University's applications rose by $23 \%$ after its basketball team advanced to the Sweet 16 in the 1993 NCAA basketball tournament.

${ }^{4}$ The ACC, SEC, SWC, Big Ten, Big Eight, and PAC Ten conferences were typically considered the "major" conferences in college basketball and football at that time. Today the ACC, SEC, Big Ten, Big Twelve, Big East, PAC Ten, and independent Notre Dame are considered the major conferences/teams.

${ }^{5}$ More detail about this literature is provided in the next section.
} 
received by a school (in the range of $2-15 \%$, depending on the sport, level of success, and type of school), and modest impacts on average student quality, as measured by SAT scores.

Because of concerns with the reliability of the self-reported SAT scores in our primary data set, we also acquired a unique administrative data set that reports the SAT scores of high school students preparing for college to further understand the average "quality" of the student that sports success attracts. These individual-level data are aggregated to the school level and allow us to analyze the impact of sports success on the number of SAT-takers (by SAT score) who sent their SAT scores to Division I schools. Again, the panel nature of the data allows us to estimate a fixed effects model to control for unobserved school-level variables. The results of this analysis show that sports success has an impact on where students send their SAT scores. This analysis confirms and expands the results from the application data set. Furthermore, this data makes it clear that students with both low and high SAT scores are influenced by athletic events. $^{6}$

Besides increasing the quality of enrolled students, schools have other ways to exploit an increased number of applications due to sports success: through increased enrollments or increased tuition. Some schools that offer automatic admission to students who reach certain quality thresholds may be forced to enroll more students when the demand for education at their school goes up. Using the same athletic success indicators and fixed effects framework, we find that schools with basketball success tend to exploit an increase in applications by being more selective in the students they enroll. Schools with football success, on the other hand, tend to increase enrollments.

Throughout our analysis, we illustrate how the average effects that we find differ between public and private schools. We find that this differentiation is often of significance. Specifically, we show that private schools see increases in application rates after sports successes that are two to four times higher than seen by public schools. Furthermore, we show that the increases in enrollment that take place after football success are mainly driven by public schools. We also find some evidence that private schools exploit an increase in applications due to basketball success by increasing tuition rates.

We think that our results significantly extend the existing literature and provide important insights about the impact of sports success on college choice. As Siegfried and Getz (2006) recently pointed out, students often choose a college or university based on limited information about reputation. Athletics is one instrument that institutions of higher education have at their disposal that can be used to directly affect reputation and the prominence of their schools. ${ }^{7}$ Our results suggest that sports success can affect the number of incoming applications and, through a school's selectivity, the quality of the incoming class. Whether or not the expenditures required to receive these indirect benefits promote efficiency in education is certainly not determined in the present analysis. Nonetheless, with the large and detailed data sets we acquired, combined with the fixed effect specification that included both college basketball and football success variables, while controlling for unobserved school-specific effects, it is our view that the range of estimates showing the sensitivity of applications to college sports performance

\footnotetext{
${ }^{6}$ In Pope and Pope (2007), we use these data to also show that sports success has a differentiated impact on various demographic subgroups of students and to illustrate the limited awareness that high school students may have with regards to the utility of attending different colleges.

${ }^{7}$ Reputation can be thought of as either academic reputation or as social/recreational reputation.
} 
can aid university administrators and faculty in better understanding how athletic programs relate to recruitment for their respective institutions.

Section 2 of this article provides a brief literature review of previous work that has investigated the relationship between a school's sports success and the quantity and quality of students that apply to that school. Section 3 describes the data used in the analysis. Section 4 presents the empirical strategy for identifying school-level effects due to athletic success. Section 5 describes the results from the empirical analysis. Section 6 concludes the study.

\section{Literature Review}

Athletics is a prominent part of higher education. Yet the empirical work on the impact of sports success on the quantity and quality of incoming students is surprisingly limited. Since the seminal work by McCormick and Tinsley (1987), there have been a small number of studies that have attempted to provide empirical evidence on this topic. In this section we review these studies to motivate the present analysis.

Table 1 provides a summary of the previous literature. ${ }^{8}$ The table is divided into two panels. Panel A describes the studies that have directly or indirectly looked at the relationship between sports success and the quantity of incoming applications. These studies have found some evidence that basketball and football success can increase applications or out-of-state enrollments. Panel B describes the studies that have looked at the relationship between sports success and the quality of incoming applications. These studies all reanalyze the work of McCormick and Tinsley (1987) using different data and control variables. The results of these studies are mixed. Some of these analyses find evidence for football and basketball success affecting incoming average SAT scores; whereas, others do not.

Differences in how the studies measured sports success make it difficult to compare the primary results of these studies. For example, Mixon and Hsing (1994) and McCormick and Tinsley (1987) use the broad measures of being in either various NCAA and National Association of Intercollegiate Athletics (NAIA) athletic divisions or "big-time" athletic conferences to proxy prominent and exciting athletic events at a university. Basketball success was modeled by Bremmer and Kesselring (1993) as being the number of NCAA basketball tournament appearances prior to the year the analysis was conducted. Mixon (1995) and Mixon and Ressler (1995), on the other hand, use the number of rounds a basketball team played in the NCAA basketball tournament. Football success was measured by Murphy and Trandel (1994) and McCormick and Tinsley as within-conference winning percentage. Bremmer and Kesselring used the number of football bowl games in the preceding 10 years. Finally, Tucker and Amato (1993) used the Associated Press's end-of-year rankings of football teams. While capturing some measures of historical athletic success, many of these variables may fail to capture the shorter-term episodic success that is an important feature of college sports.

Perhaps more important to the reliability of the results of these studies than the differences in how sports success was measured are the data limitations they faced and the resulting

\footnotetext{
${ }^{8}$ Other papers in this literature (as pointed out by a referee) include Mixon, Trevino, and Minto (2004), Tucker (2004, 2005), Mixon and Trevino (2005), Goidel and Hamilton (2006), McEvoy (2006), and Tucker and Amato (2006). These papers adopt similar identification strategies for estimating the quantity and quality effects as those described in Table 1.
} 
identification strategies employed. All of the analyses except for that of Murphy and Trandel (1994) use a single year of school information for a limited set of schools. ${ }^{9}$ For example, Mixon and Ressler (1995) collected data from Peterson's Guide for one year and 156 schools that participate in Division I-A collegiate basketball. The lack of temporal variation in these data necessitates a cross-sectional identification strategy. A major concern with cross-sectional analyses of this type is the possibility that there is unobserved school-specific information, correlated with sports success, that may bias estimates. In fact, much of the debate surrounding differences in estimates in these cross-sectional analyses hinges on arguments about the "proper" school quality controls to include in the regressions. Another concern is the college guide data typically used. It is widely known that the self-reported data (especially data on SAT scores) from sources such as U.S. News \& World Report and Peterson's can have inaccuracies or problems with institutions not reporting data. ${ }^{10}$

The present study attempts to overcome some of the data and identification strategy limitations of this earlier literature. The goal is to acquire more complete data sets and to provide an identification strategy that seeks to better control for unobserved school-specific effects. The identification strategy will be developed to jointly estimate the impact of reasonable measures of both basketball and football success on the rates and quality of incoming applications. Furthermore, we explicitly analyze the heterogeneous impact that sports success has on public and private schools. ${ }^{11}$ In doing this, it is our hope that a broader, more consistent picture of the relationship between athletics and academics will emerge.

\section{Primary Data Sources}

Students respond to several pieces of information when deciding where to go to college. Some types of information that have been shown to affect college choice include the costs of attending college (e.g., tuition, living costs, scholarships; see Fuller, Manski, and Wise 1982; Avery and Hoxby 2004) and attributes of the school (e.g., college size, location, academic programs, reputation; see Chapman 1981). Athletic success likely has two primary components that affect college choice decisions: historic athletic strength and episodic athletic strength. The data sets we use allow us to control for historic athletic strength and analyze episodic athletic strength.

We use three primary data sets to conduct our empirical analysis. Each of these data sets is compiled so that the unit of observation is an institution of higher education that participates in Division I basketball or Division I-A football. The first data set is a compilation of sports rankings, which are used to measure athletic success. The second data set provides school characteristics, including the number of applications, average SAT scores, and the enrollment size for each year's incoming class of students. The third data set provides the number of SAT scores sent to each institution of higher education. The main features of these three data sets are discussed in more detail below.

9 Temporal variation typically enters the regression via a variable that reflects the aggregate sports success over the 1015 years prior to the year of the school data.

${ }^{10}$ See, for example, Steve Stecklow's April 5, 1995, article in the Wall Street Journal entitled "Cheat Sheets: Colleges Inflate SATs and Graduation Rates in Popular Guidebooks."

${ }^{11}$ We are grateful to the referees of this paper who suggested that public and private schools should be treated differently in our analysis. 


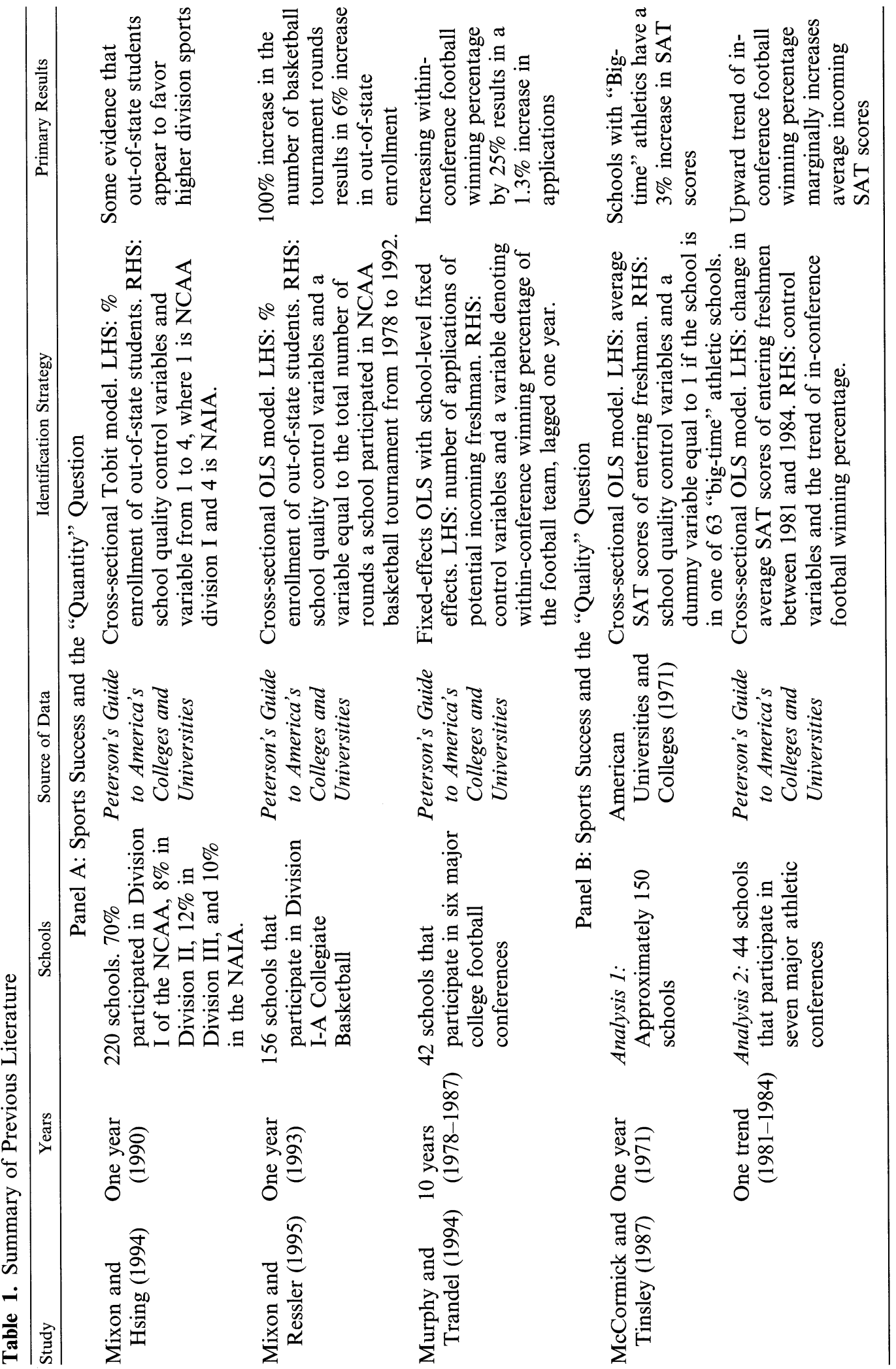




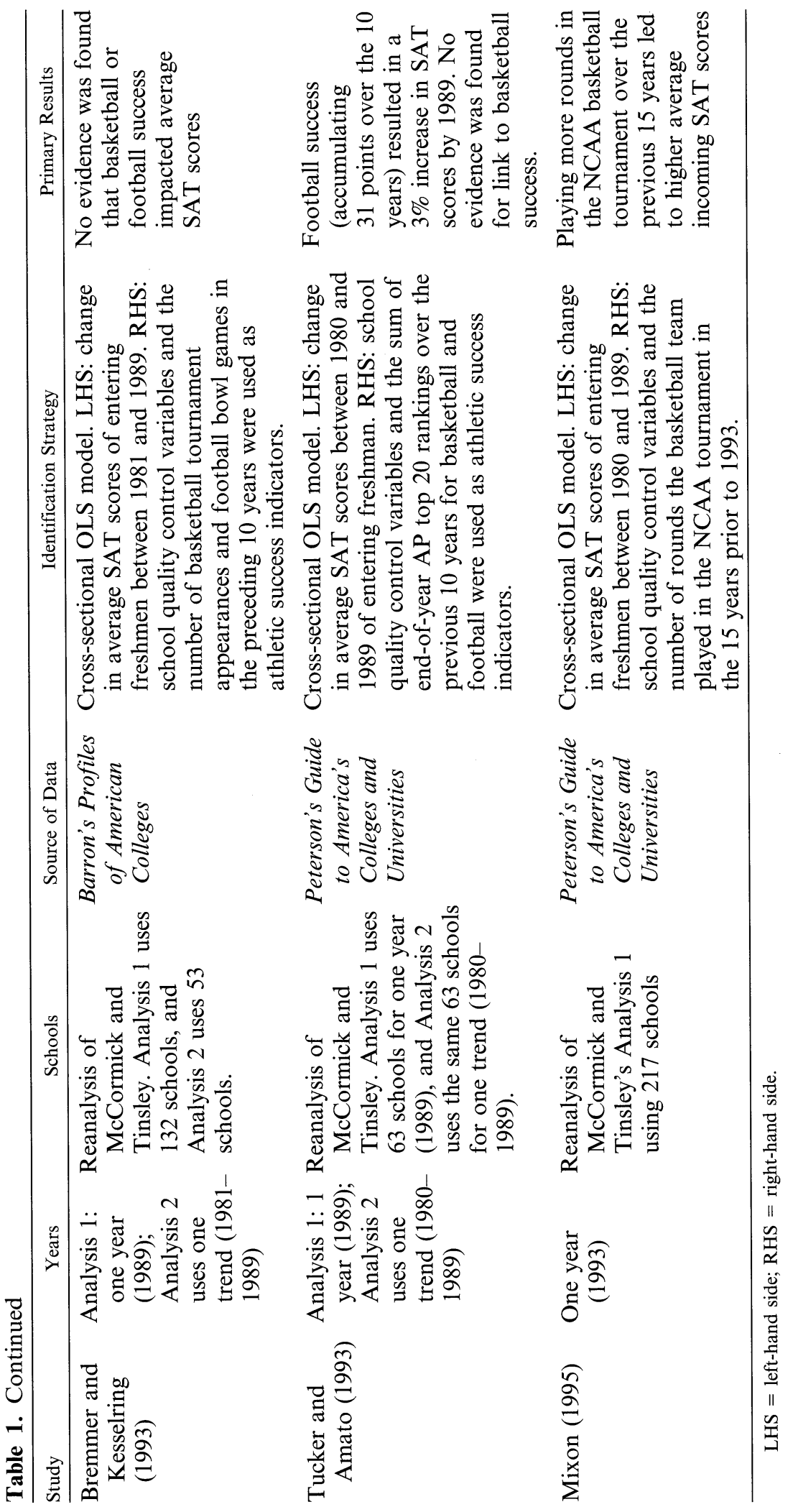




\section{Football and Basketball Success Indicators}

Our indicator of football success is the Associated Press's college football poll. The Associated Press has produced their "AP College Football Poll" annually since 1936. They rank NCAA Division I-A football teams based on game performances throughout the year. We collected the end-of-season rankings for all teams finishing in the top 20 between the years 1980 and 2003. ${ }^{12}$ Although this indicator does not incorporate all measures of success (for example, big wins against key rivals, exciting individual players on a team), it is probably a reasonable proxy of football success each year. It also provides a consistent measure of success for all teams in our sample over the time frame of our data.

It is widely agreed that the greatest media exposure and indicator of success for a men's college basketball team (particularly on a national level) comes from the NCAA college basketball tournament. "March Madness," as it is often called, takes place at the end of the college basketball season during March and the beginning of April. It is a single elimination tournament that determines who wins the college basketball championship. Before 1985, 48-53 teams were invited to the tournament each year. Since 1985, 64 teams have been invited to play each year. ${ }^{13}$ We collected information on all college basketball teams that were invited to the tournament between 1980 and 2003. From these data we created dummy variables that indicate the furthest round in which a team played. In our analysis, we use the rounds of $64,16,4$, and champion. A team's progress in the NCAA tournament provides a good proxy of a basketball team's success in any given year during the time frame of the data.

To prepare for the identification strategy described in section 4 , dummy variables were created for schools' football programs that were ranked in the AP top 20 and top 10 and for the football champion of each year. Similarly, dummy variables were created for schools' men's basketball programs that made it to the NCAA tournament, the Sweet 16, and the Final Four and for the basketball champion of each year. ${ }^{14}$ Although less parsimonious as continuous measures of athletic performance (i.e., the number of games played in the NCAA tournament), these dummy variables will allow for an analysis that provides a sense of the different marginal effects of various categories of football and basketball success. Certainly the marginal effect of winning in the first round of the NCAA tournament is much different than winning in the last round. Furthermore, the lagged counterparts to the dummy variables will help us to better understand the persistence of any impact of college sports success on the quantity and quality of students at schools.

\section{College Data}

As discussed in Section 2, a weakness of earlier studies on the impacts of athletic success was the limited number of observations across time and across schools. In an attempt to rectify this shortcoming, we purchased access to a licensed data set from the Thomson Corporation that contains detailed college-level data. Thomson Corporation is the company that publishes the well-known Peterson's Guide to Four Year Colleges. Most of the studies we outlined in the

\footnotetext{
${ }^{12}$ Both football rankings and basketball tournament result data can be obtained at www.infoplease.com.

${ }^{13}$ Forty-eight teams were invited in 1980, 1981, and 1982. In 1983, 52 teams were invited. In 1984, 53 teams were invited. Currently 65 teams are invited, but one of two teams is required to win an additional game before entering the round of 64 .

${ }^{14}$ These rounds are typically considered "special" rounds resulting in extra recognition to a team.
} 
introduction actually culled applications and SAT data from the print versions of this guide. The data set includes annual statistics on all major colleges and universities in the United States from 1983 to 2002 . We restrict the data set to the 332 schools that participated in NCAA Division I basketball or Division I-A football between 1983 and 2002.

We collected four other variables to use as controls that are not available for every year in our version of the Peterson's data set. Average nine-month full-time professor salary and total annual cost of attendance at each school were collected from the Integrated Post Secondary Education Survey that is conducted by the National Center for Education Statistics. The number of high school diplomas given out by state was also collected from the National Center of Education Statistics. The per capita income between 1984 and 2002 by state was collected from the Bureau of Labor Statistics. Both of these state-level variables were then linked to all colleges within a state.

Table 2 displays summary statistics of the variables used in our analysis from the Peterson's data set. The first three columns give the descriptive statistics for the approximately 330 schools in our sample for 1983, 2000, and all years combined. We report the percentage of incoming students who scored above a certain threshold on the math and verbal sections of the SAT, along with total applications received and total freshman enrollment. We also report summary statistics of the four control variables that we merged into the college data set. Looking at Table 2, it can be seen that over the 20 -year period in our sample, schools have increased in size and quality of their incoming students. Columns 4-6 give the same summary statistics for the subset of schools in our sample that finished at least once in the top eight teams of the NCAA basketball tournament or in the top 10 teams of the Associated Press College Football Poll between 1980 and 2003. These schools are on average larger and have a slightly higher quality of students than the other schools in the sample. Columns 7 and 8 give the same summary statistics for public and private schools in our sample. Private schools on average have smaller enrollments and higher quality students and are more expensive to attend. Columns 4-8 will be useful when interpreting the size of the effects presented in the results section.

\section{SAT Test-Takers Database}

The third data set that we use is derived from the College Board's Test-Takers Database (referred to as SAT database in the remainder of the paper). ${ }^{15}$ It includes individual-level data for a $25 \%$ random sample of all SAT test-takers nationwide with graduation cohorts between 1994 and 2001. It also includes a 100\% sample of SAT test-takers that are Californians, Texans, African American, or Hispanic. ${ }^{16}$ Because students can take the SAT several times, the College Board divided the data into cohorts according to the year in which the students are expected to graduate. For example, the 1994 cohort group contains students who took the SAT who are expected to graduate in the spring of 1994 and apply for college the following fall. ${ }^{17}$ The SAT

\footnotetext{
${ }^{15}$ We thank David Card, Alan Krueger, the Andrew Mellon Foundation, and the College Board for help in gaining access to this data set.

${ }^{16}$ The reason for the oversampling of two states and races is because the data set was originally acquired to analyze the impact of changes in the affirmative action program in Texas and California.

${ }^{17}$ The data report the SAT score and background characteristics of the most recent test and survey taken. For most students, this is at the beginning of their senior year in high school.
} 


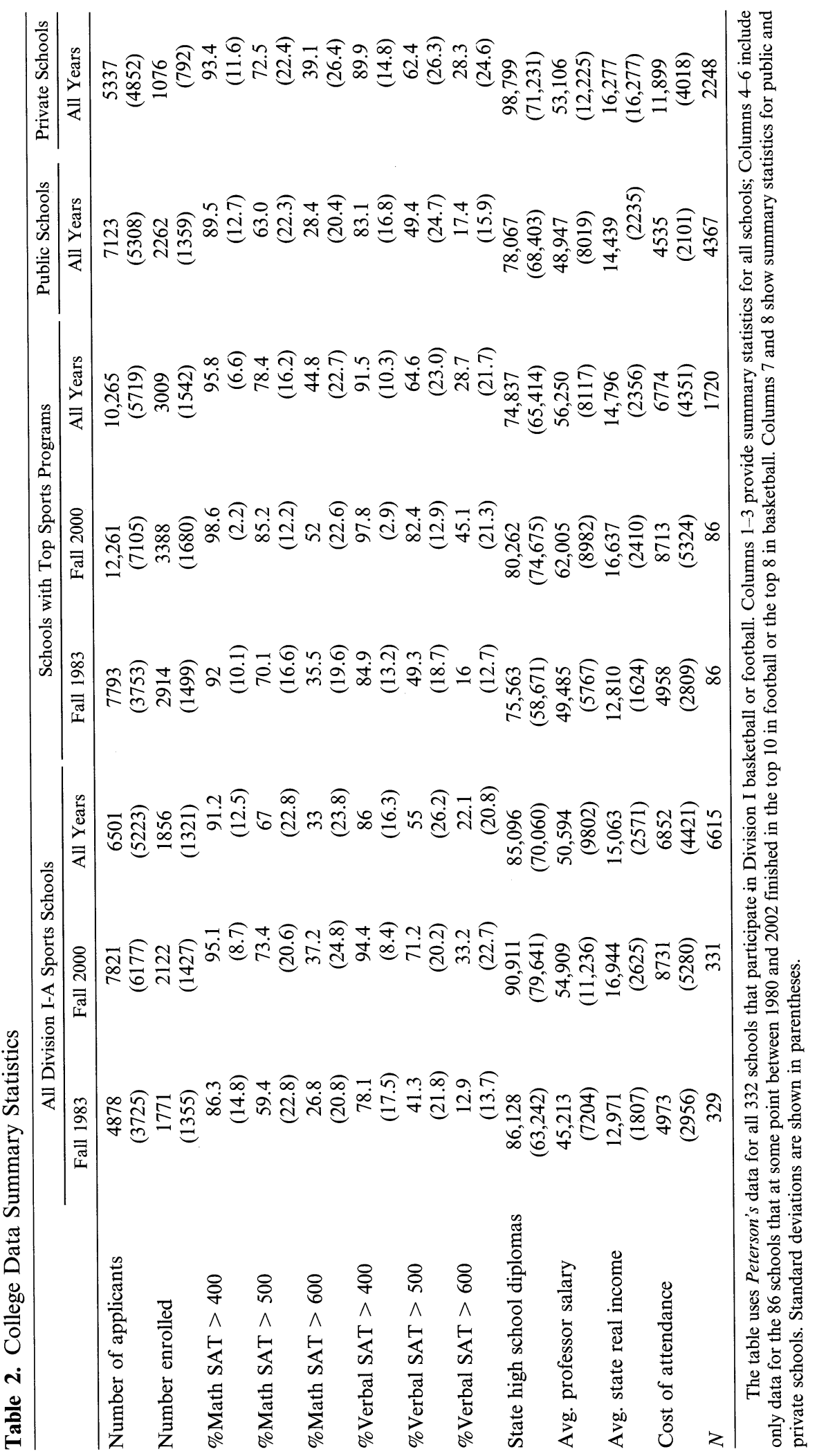


database provides demographic and other background information in the Student Descriptive Questionnaire component of the SAT.

After completing the test and questionnaire, students may indicate up to four colleges where their test scores will be sent for free. Students may also send their scores to additional schools at a cost of $\$ 6.50$ per school. The data set identifies up to 20 schools to which a student has requested his scores be sent. ${ }^{18}$ The median number of schools to which a student requested his scores be sent was five across all years in our sample. We restrict the data set to students who sent their scores to at least one of the 332 schools that played NCAA Division I basketball or Division I-A football. We also weighted the observations so that the data are representative of all potential college applicants to each of these 332 schools. ${ }^{19}$

The SAT data set will allow us to further explore how college applicants with different SAT exam scores are affected by football and basketball success. Unlike the self-reported data from sources such as Peterson's Guide, all the data in the SAT database are reported, and inaccuracies are almost nonexistent. These data also allow us to better analyze the impact of sports success on the SAT score sending of students with high, middle, and low SAT scores. By aggregating these high-quality individual-level data to the school level, the impact of sports success on the quality of incoming SAT scores that a school receives can be analyzed. These results will complement the analysis conducted with the applications database. ${ }^{20}$

\section{Empirical Strategy}

Many school characteristics cannot be observed by the econometrician, yet these unobservables are likely correlated with both indicators of sports success and the number of applications received by a school. The unobservable component is likely to include information about scholastic and athletic tradition, geographic advantages, and other information on the true quality of the school. Without adequately controlling for these unobservables, they would likely confound the ability to detect the impact of athletic success on the quantity and quality of incoming students. The nature of the data we have compiled allows us to plausibly control for the unobservables associated with each school.

Even after including school fixed effects and linear trends for each school, it is always worrisome that schools that perform well in sports in a given year are schools that have recently improved academically as well. If this is the case, the effects of sports success on application rates and student quality may be spurious. To try and deal with this issue, we include one-year lead sports dummy variables in our regression to estimate the effect that having sports success

\footnotetext{
${ }^{18}$ Less than $1 \%$ of students sent their scores to more than 14 schools.

${ }^{19}$ The weight is 1 for observations from students who are included in the sample with probability 1 and 4 for those who are included in the sample with probability .25 .

${ }^{20}$ Sending an SAT score to a school is not the same as applying to that school. However, it may be a good proxy. Card and Krueger (using the same SAT test-takers data set) tested the validity of using sent SAT scores as a proxy for applications. They compared the number of SAT scores that students of different ethnicities sent with admissions records from California and Texas and administrative data on the number of applications received by ethnicity. They conclude that "trends in the number of applicants to a particular campus are closely mirrored by trends in the number of students who send their SAT scores to that campus, and that use of the probability of sending SAT scores to a particular institution as a measure of the probability of applying to that institution would lead to relatively little attenuation bias" (2004, p. 18).
} 
next year has on this year's applications. If the results suggest that future sports success does not predict current admission figures, this would lend credibility to our empirical strategy.

One concern that arises with the use of SAT scores over our sample period is that the SAT was recentered in 1995. Our analysis includes fixed effects for academic years that properly control for any recentering effects that simply cause a shift in the distribution of SAT scores. However, the recentering that took place in 1995 not only shifted the distribution but also changed its shape. This reshaping of the distribution could bias our results if the incoming students from schools that perform well in sports are clustered at a location in the distribution that was heavily skewed because of the recentering. We are unable to rule out this bias because we lack data on the entire distribution of SAT scores for incoming students. However, this bias (which could go in either direction) is likely to be small after controlling for year fixed effects and is unlikely to cause the results that we find at several different cutoffs in the SAT distribution. $^{21}$

\section{Econometric Specification Using Peterson's Data}

The econometric specification we employ in conjunction with the Peterson's data set takes advantage of the panel design of the data. We use a fixed effects model where the fixed effects control for year-specific and school-specific unobserved heterogeneity. We also include a linear trend for each school to try to control for heterogeneous trend rates. We include several additional variables on the right-hand side of the equation to further control for quality characteristics of the schools. The econometric specification we use is the following:

$$
Y_{i, t}=\alpha_{i, t}+S_{i, t+1}+S_{i, t} \beta+S_{i, t-1} \delta+S_{i, t-2} \gamma+S_{i, t-3} \theta+X_{i, t} \phi+\varepsilon_{i, t},
$$

where $Y_{i, t}$ represents either the log applications, log enrollments, or log real tuition of school $i$ during year $t$, depending on the regression being run. We also ran these same regressions separately for public and private schools to understand if sports success has a heterogeneous impact for schools that are funded and organized differently. $S_{i, t}$ is a set of dummy variables indicating the level of sports success that school $i$ had during year $t$. We include lead and current year as well as up to three lags for each sports variable in our model. $X_{i, t}$ is a set of four control variables commonly used in the literature to control for the quality of the school: $\log$ total cost to attend school, log average professor salary (lagged one year), log average real income in the state in which the school is located, and the number of high school diplomas awarded in the state in which the school is located during year $t$. It is important to note that rather than using total applications as the dependent variable (which is the dependent variable used in other studies looking at the effect of sports success on applications), we use log applications. Failure to include the log of applications results in significantly overweighting large schools compared to small schools. Furthermore, our intuition suggests that sports success will increase applications by a given percentage across schools rather than by a given level. If Equation 1 is correctly specified, we should then be able to identify the impact of athletic success on the number of applications received by a school.

\footnotetext{
${ }^{21}$ We are grateful to a referee for pointing this issue out. As a sensitivity check, we ran our analysis separately for the years prior to and after the recentering that took place in 1995 and found the results to be stable between these two time periods.
} 


\section{Econometric Specification Using SAT Database}

Our econometric specification in Equation 1 can be adapted for use in conjunction with the SAT data in the following manner:

$$
Y_{i, t}^{j}=\alpha_{i, t}+S_{i, t+1}+S_{i, t} \beta+S_{i, t-1} \delta+S_{i, t-2} \gamma+S_{i, t-3} \theta+X_{i, t} \phi+\varepsilon_{i, t} .
$$

This is the same specification as Equation 1 except that the dependent variable represents the $\log$ number of SAT scores received by school $i$ in year $t$ from the $j$ population group. More specifically, we calculate the number of SAT scores sent to schools by SAT exam score groupings. This estimation allows us to compare the coefficients on the sports variables across groups to see if certain groups are more likely to respond to sports success than others. We again run these same regressions separately for public and private schools to understand if sports success has a heterogeneous impact on sent SAT scores for schools that are funded and organized differently.

\section{Timing of the Impact of Athletic Success}

Understanding when prospective students apply to college in relation to the football and basketball seasons is crucial in determining which lags of our athletic success variables should affect the left-hand side of Equation 1. Fall admission application deadlines vary by school. They can occur any time between November and August before the expected fall enrollment period. Furthermore, students often must send letters of recommendation and SAT scores to the school well before the actual deadlines. Figure 1 illustrates the distribution of application deadlines in our sample in 2003 using the Peterson's college data set. The label "continuous" in Figure 1 refers to those schools that have a rolling application period, rather than a specific deadline. By 2003, nearly half of the schools in our sample have application deadlines in May or earlier.

The NCAA Division I-A football season finishes at the beginning of January. The NCAA basketball tournament finishes at the end of March or beginning of April. Therefore, if these sports influence the number of applicants a school receives, we would expect an effect on the current year variables. This means that a successful football team that finishes in January or a successful basketball team that finishes in March will affect application decisions for students enrolling that fall. However, given the timing of when applications were likely prepared and submitted, and the football and basketball seasons, one would possibly expect an equally large impact of football and basketball to be on the first lag of an athletic success variable (especially for basketball, which ends three months after football). The second and third lags will give an indication of the persistence of the athletic success which occurred two to four years earlier.

\section{Results}

\section{Results Using Peterson's Data}

Table 3 presents the results for our specification in Equation 1 using the Peterson's college data set. The first column reports the results from a regression of log applications on the controls and the sports variables for all schools in our sample. Standard errors in this and all 


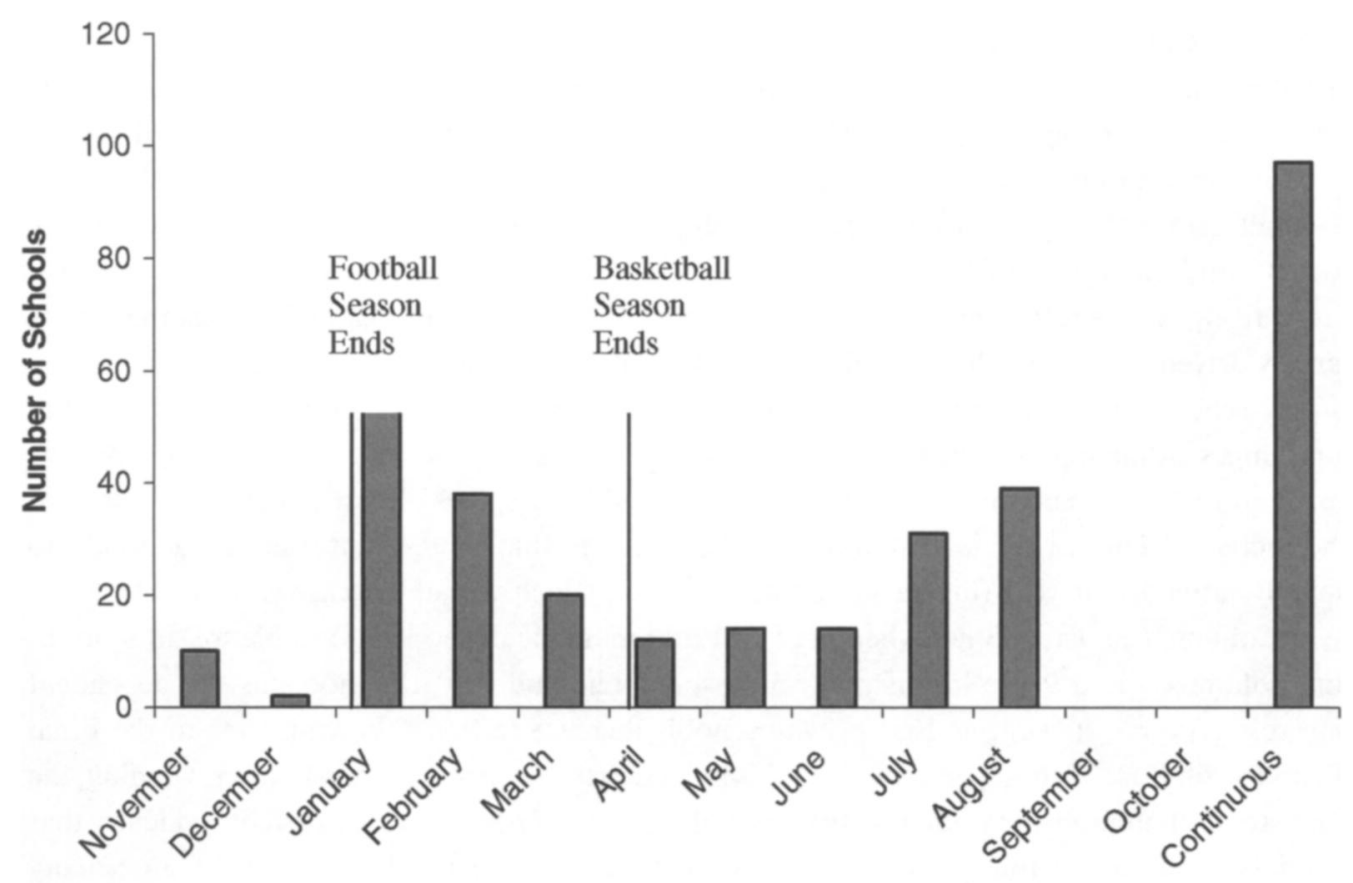

Month of Application Deadline

Figure 1. Application Deadlines

other tables presented below are computed using Eiker-White Robust standard errors. For basketball, the results suggest that being one of the 64 teams in the NCAA tournament yields approximately a $1 \%$ increase in applications the following year, making it to the "Sweet 16 " yields a $3 \%$ increase, the "Final Four" a 4-5\% increase, and winning the tournament a 7-8\% increase. The impact of the athletic lags is as we expected. Although there is an effect of winning on the current year's applications, the largest effect comes in the first lag. By the third lag, the effect has usually diminished substantially. Not all of the coefficients are significantly different than zero with conventional tests. However, almost all coefficients are suggestive and several are significant. For football, the results suggest that ending the season ranked in the top 20 in football yields approximately a $2.5 \%$ increase in applications the following year, ending in the top 10 yields a $3 \%$ increase, and winning the football championship a 7-8\% increase. The largest effect is on the current football sports variable, along with a small effect on the first lag. Columns 2 and 3 of Table 3 report the results for log application regressions run separately for public and private schools. The results from these regressions suggest that for basketball private schools receive two to four times as many additional applications than public schools as they advance through the NCAA tournament, while the results for football are less conclusive. Furthermore, the application impact for private schools appears to be more persistent. For example, when a private school advances to the Sweet 16 , it enjoys an $8-14 \%$ increase in applications for the next four years; whereas, a public school sees only a $4 \%$ increase for the next three years.

Besides being more selective, schools might react to increased applications by increasing their enrollment or tuition levels. Table 3 presents the impact of sports success on these two 
variables. Column 4 uses log enrollment as the dependent variable in the now familiar specification for all schools, and columns 5 and 6 use log enrollments of public and private schools as the dependent variable. The results indicate that teams that have basketball success do not enroll more students the following year. However, schools that perform well on the football field in a given year do increase enrollment that year. Teams that finish in the top 20 , top 10 , and champion in football on average enroll $3.4 \%, 4.4 \%$, and $10.1 \%$ more students, respectively. These results are all significant at the $1 \%$ level. Columns 5 and 6 suggest that this is largely driven by public schools. This increased enrollment could come from the fact that many public schools give guaranteed admission for certain students. For example, a school that guarantees admission for in-state students with a certain class rank or test score may be required to enroll many more students if demand suddenly spikes. Another possible reason for the increased enrollment is that more of the students that a university admitted decide to actually attend that year (higher matriculation rate), which would increase enrollment.

Column 7 of Table 3 uses the log of real tuition as the dependent variable for all schools, and columns 8 and 9 use $\log$ of real tuition of public and private schools as the dependent variable. The results suggest that private schools increase tuition following trips to the Final Four (results are also suggestive for tuition increases by private schools after winning the basketball championship) but not for football success. There is no consistent evidence that public schools adjust tuition because of sports success. However, this is likely because many public schools have political constraints on increasing tuition.

Table 4 presents results using SAT data in the Peterson's data set on the incoming students to see how sports success enables schools to attract higher quality students. Columns 1-3 show results from specifications that use the percent of incoming students who scored above 500 on the SAT in math as the dependent variable for all schools, public schools, and private schools. Columns 4-12 show results for specifications where the dependent variable is percent of incoming students scoring above 500 in the verbal, above 600 in the math, and above 600 in the verbal section of the SAT. Overall, the coefficients in these specifications mirror to some degree the log applications results. The results are strongest for basketball. The coefficients on the football variables are suggestive, but not significant. The coefficients on the basketball variables when all schools are included suggest that schools that do well in basketball are able to recruit an incoming class with $1-4 \%$ more students scoring above 500 on the math and verbal portions of the SAT. Similarly, these schools could also expect $1-4 \%$ more of their incoming students to score above 600 on the math and verbal portions of the SAT. As can be seen in Table 3, however, to examine the effect of sports success on SAT score categories in the Peterson's data set, approximately 1600 observations of the 5335 are dropped due to missing SAT data. Therefore it is important to further examine the "quality" effect using the SAT data set.

\section{Results Using SAT Database}

The results for the impact of sports success on different SAT score subgroups are presented in Table 5. These results stem from regressions using SAT-sending rates by SAT subgroup and by public and private schools as the dependent variables in Equation 2. The results indicate that sports success increases SAT-sending rates for all three SAT subgroups. However, the lower SAT scoring students (less than 900) respond to sports success about twice 


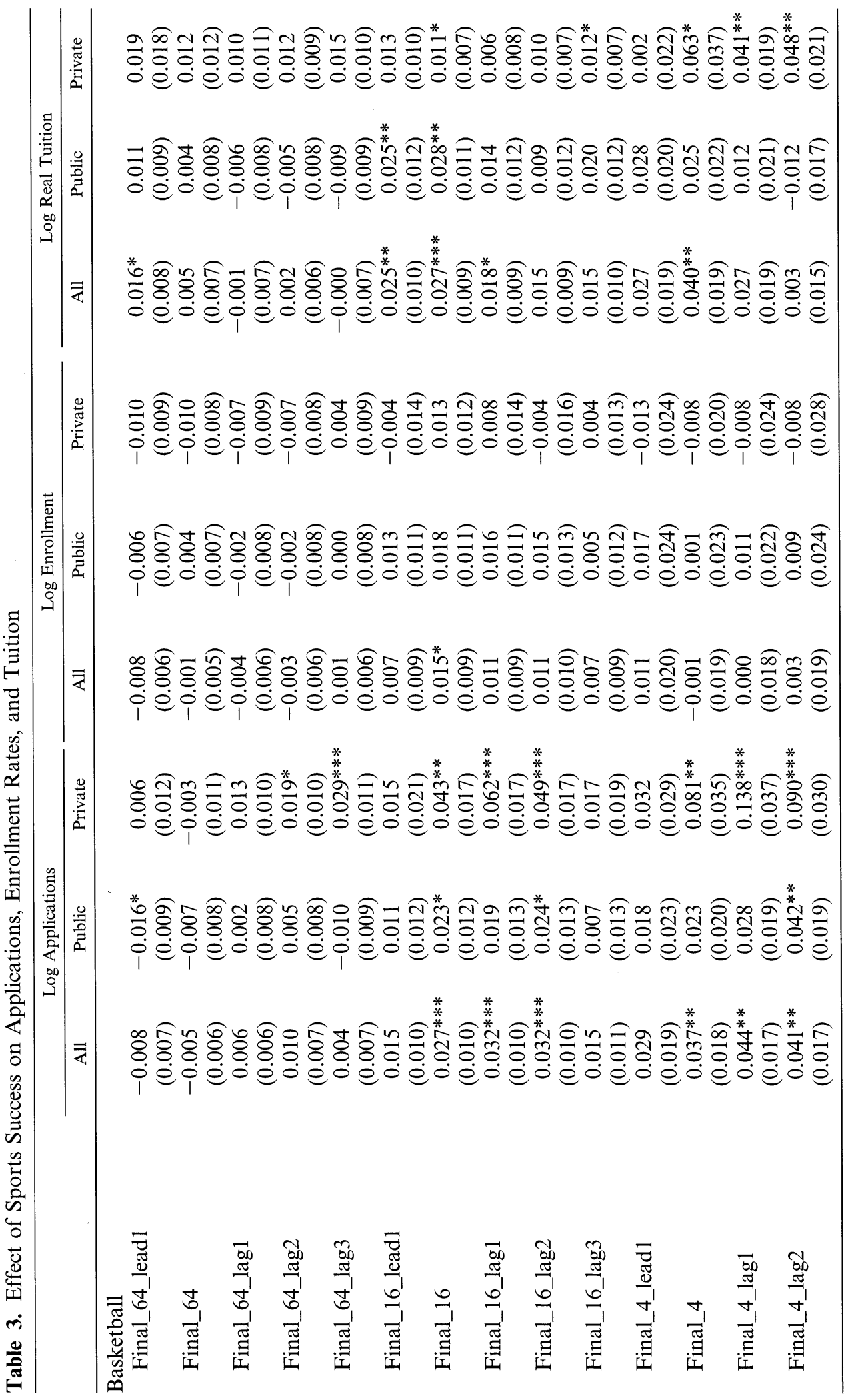




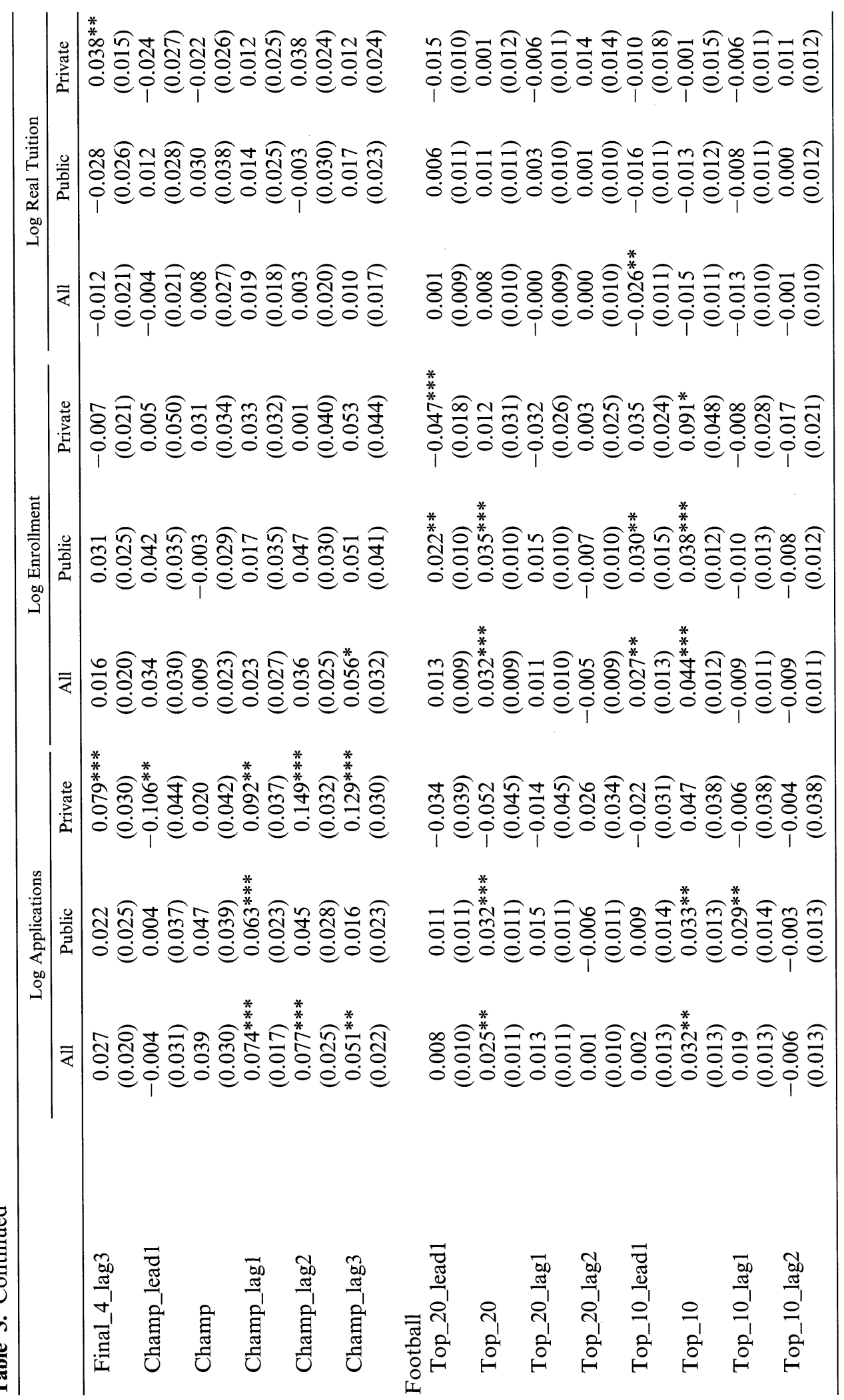




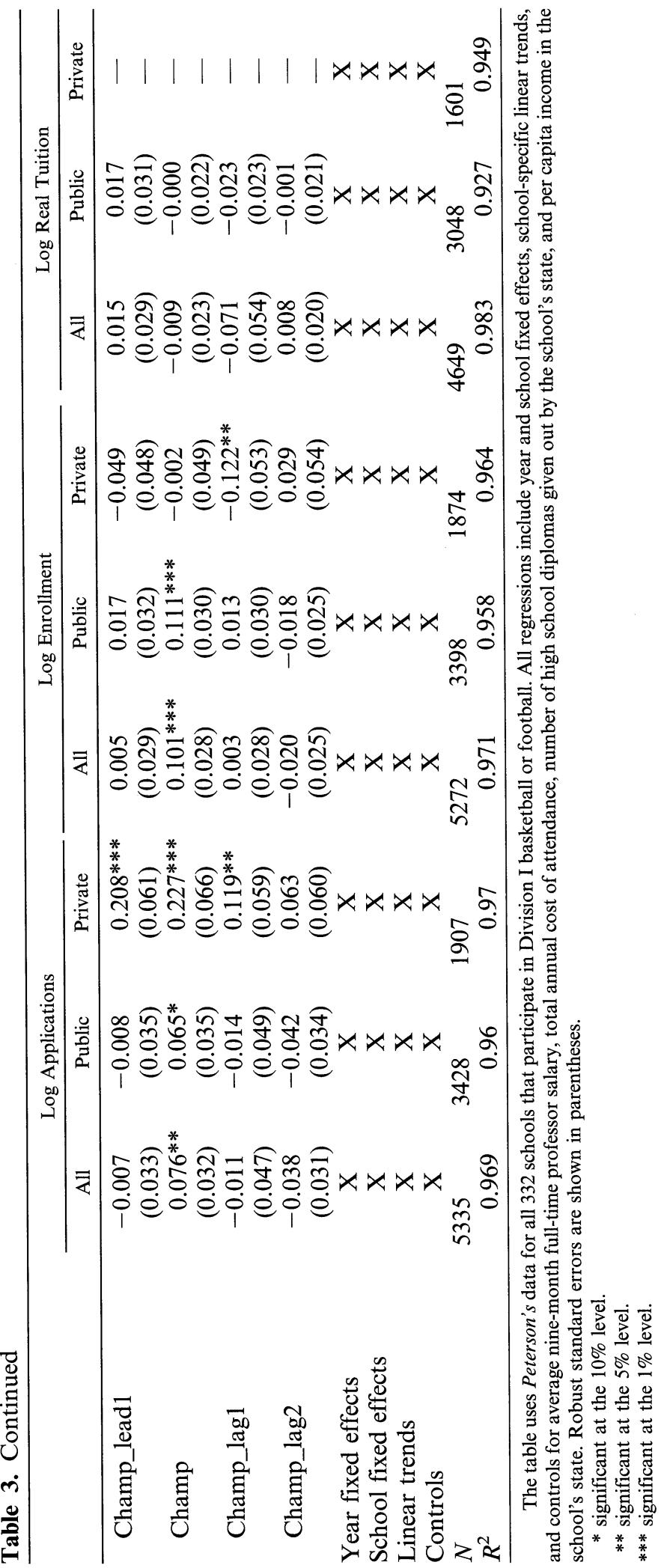


as much as the higher SAT scoring students. For example, schools that win the NCAA basketball tournament see an $18 \%$ increase a year later in sent SAT scores less than 900, a $12 \%$ increase in scores between 900 and 1100, and an $8 \%$ increase in scores over 1100. Also, private schools tend to see a larger increase in sent SAT scores after sports success than for public schools (although this does not appear to be true for the basketball championship and high SAT scores). For example, it can be seen that when a private school reaches the Sweet 16 in the NCAA basketball tournament, they have two to three times as many SAT scores sent to them as the pubic schools in the first and second periods after the basketball success. Furthermore, the effect tends to persist longer for the private schools than the public schools, as can be seen on lags 2 and 3. A similar difference between public and private schools can be seen for football. The championship round cannot be compared, as there were no private schools that won the football championship during this time period.

Overall, these results suggest that schools that have athletic success are not receiving extra SAT scores solely from low performing students. The results also greatly strengthen the SAT results derived from the Peterson's data. It appears that athletic success does indeed present an opportunity to schools to be either more selective in their admission standards or enroll more students while keeping a fixed level of student quality.

\section{Specification and Robustness Checks}

Although the specification described in Section 4 and used to produce the results presented in Section 5 is our a priori preferred specification given our data, there are other potential specifications that could be used to analyze the impact of sports success on the quantity and quality of student applications. ${ }^{22}$ For example, because of the panel nature of our data, one could use the random effects model rather than the fixed effects model. Therefore we also ran a random effects model and compared it with the fixed effects model using a Hausman test. The Hausman test rejected the null hypothesis that the coefficients estimated by the random effects estimator were the same as the ones estimated by the fixed effects estimator (Prob $>\chi^{2}=$ 0.0000 ). Thus the fixed effects model appears to be appropriate for our analysis. Nevertheless, it is comforting that when comparing the random effects coefficients in column 2 of Table 6 with the fixed effects estimates in column 1, the coefficients are similar in magnitude and significance.

Another specification assumption we made was using the log-linear functional form for our regressions. Remember that we chose this functional form because it should help mitigate the problem of overweighting large schools relative to small schools. This assumption makes sense if applications tend to increase by a given percentage across schools rather than by a given level due to sports success. However, despite this a priori intuition, we reestimated our primary model using all schools, but this time using the total applications as our dependent variable that were not scaled. As can be seen in column 3 of Table 6 , the results closely mirror our log applications results. For example, the increase of 420 applications we see for the Final_4_lag1 variable is approximately a $6 \%$ increase in applications for the average school in our sample; whereas, our original specification suggests a $5.5 \%$ increase. We also run a regression where the

\footnotetext{
${ }^{22}$ We are again grateful to the referees of this paper for bringing to our attention the need for some of these robustness checks.
} 


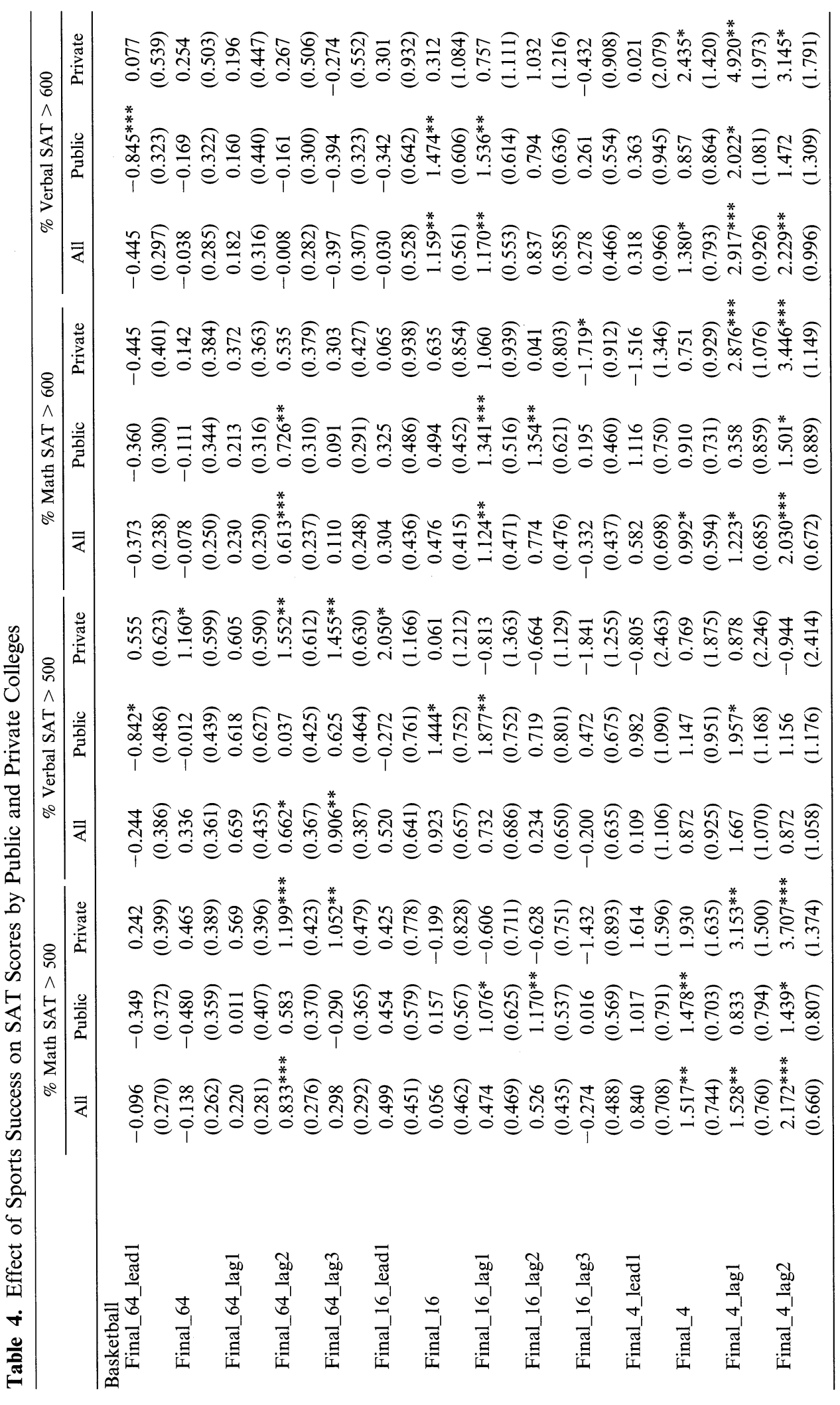




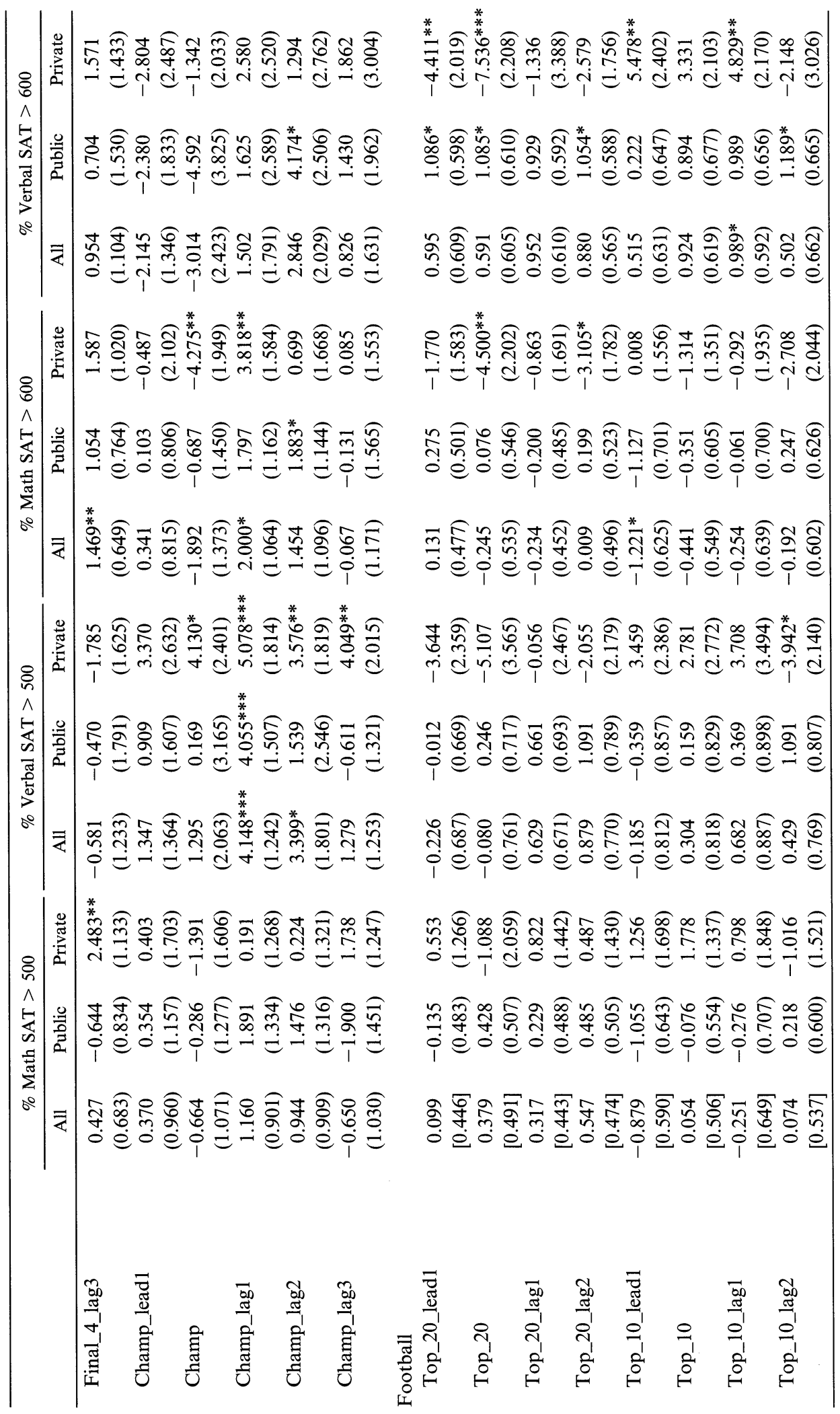




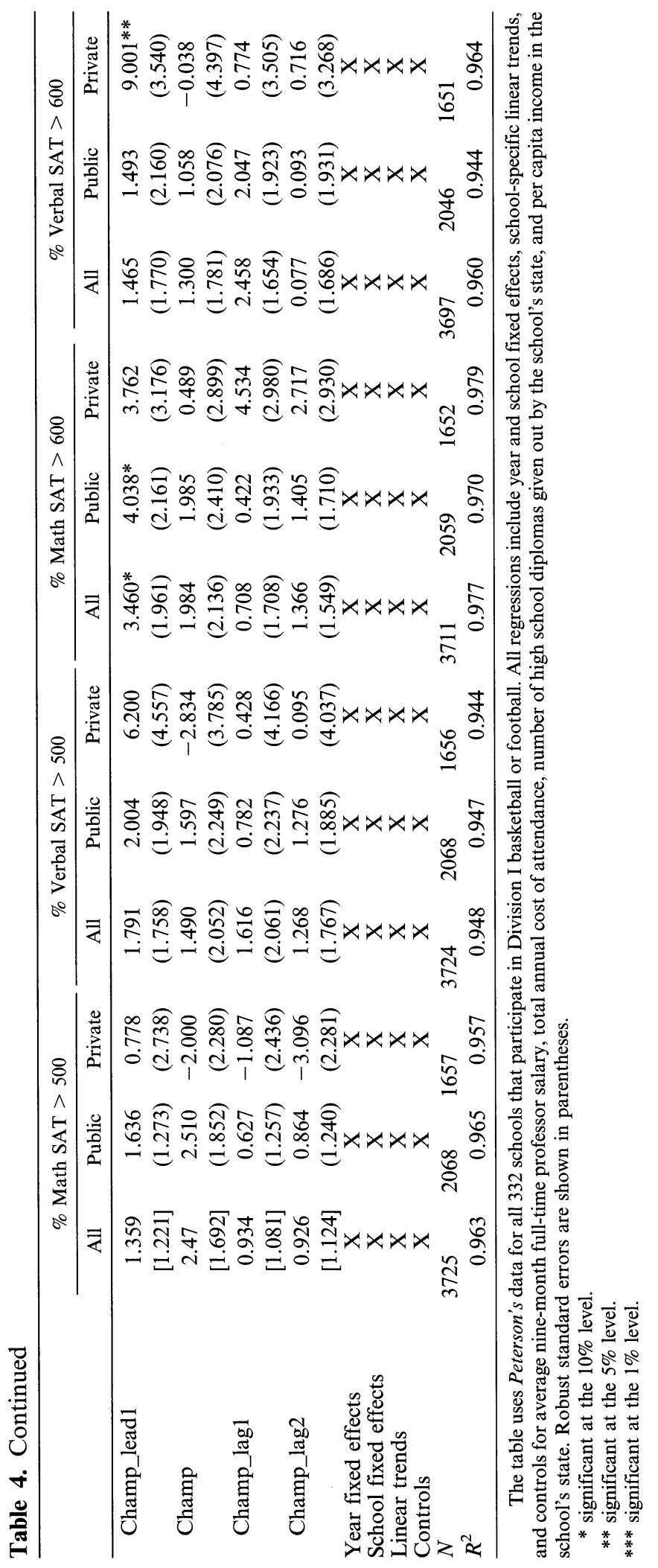


dependent variable is the total applications in a given year divided by the number of these applications that actually enrolled in the school. This specification, like the log of applications, scales applications to help account for the size of the school. Column 4 presents the results of this regression and shows that for basketball the results are similar to our original results (although somewhat larger in magnitude); whereas, the football results are less significant (and smaller in magnitude). We think this reflects an issue of endogeneity, since we showed in Table 3 that enrollments do increase after sports success, especially for football schools. Thus, as applications increase, so do enrollments, so that the impact in our dependent variable is naturally dampened. Overall, these regressions do not suggest that using the log of applications was inappropriate.

Another potential concern is that our school fixed effects and linear trends do not fully capture changes in the quality of schools over time and therefore may confound the analysis. Although the original specification includes four additional school quality variables, it may be useful to include additional variables in the $X_{i, t}$ portion of the specification to better control for changes in school quality over time. The reason for not including these variables in the original specification is because they are typically not available for all of the schools or all of the time period of our analysis. Therefore, using additional control variables comes at the cost of statistical power. Nonetheless, we did acquire the following additional school quality variables for schools over time that have appeared in higher education literature: publication and citation data, federal grant dollars acquired, percentage of students that go on to graduate school, faculty to student ratio, percentage of student body that are graduate students, per capita expenditure on instruction, number of national merit achievement scholars, percentage of faculty with a doctorate, and the number of volumes in the school library. ${ }^{23}$

We include these variables in $X_{i, t}$ as a robustness test. Column 5 of Table 6 presents the results from this regression. Although using these additional controls causes us to lose approximately $25 \%$ of our sample, these results also closely mirror our original specification. A final unreported specification check that was suggested by a referee was to add some geographic variables in case changes in application rates are somehow spatially correlated within regions. A specification that added census regions found virtually no change in the coefficients on our sports success variables. Therefore, as a whole these specification and robustness checks suggest that our original specification is a reasonably robust one for the task of identifying the impact of sports success on the quantity and quality of student applications.

\section{Conclusion and Future Research}

"How does playing major college football or men's basketball in a highly commercialized, profit-seeking, entertainment environment further the educational purpose of your member institutions?" Fully answering Representative Thomas's question that he posed to the president

\footnotetext{
${ }^{23}$ Publication and citation data came from Thomson's University Science Indicators database, federal grant dollars and per capita expenditure on instruction were derived from IPEDS, and all other additional variables were derived from the Peterson's data we purchased. It should be noted that in an effort to reduce the number of observations that were dropped, some of the observations were interpolated or extrapolated from observations on a school level where data were not collected every year.
} 


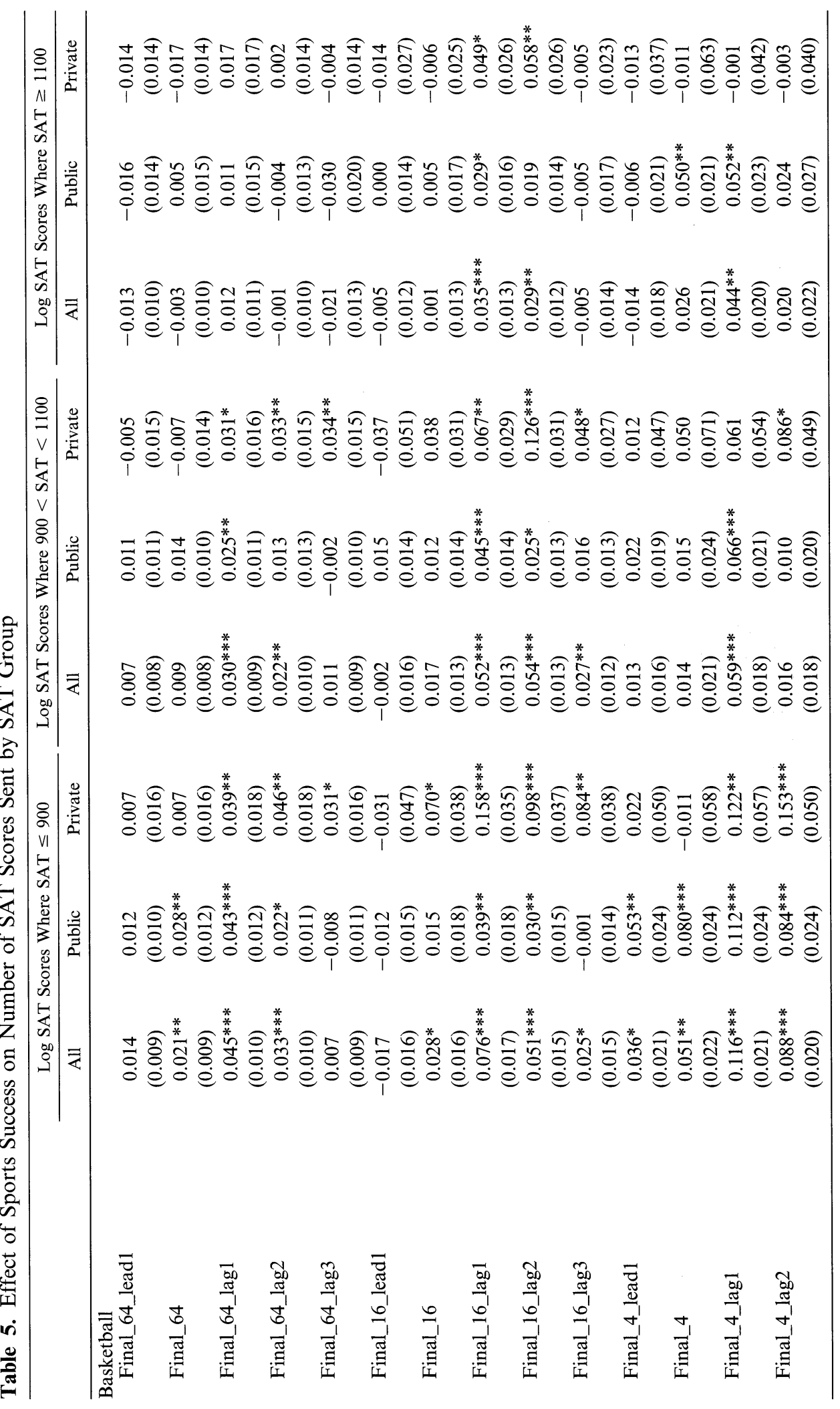




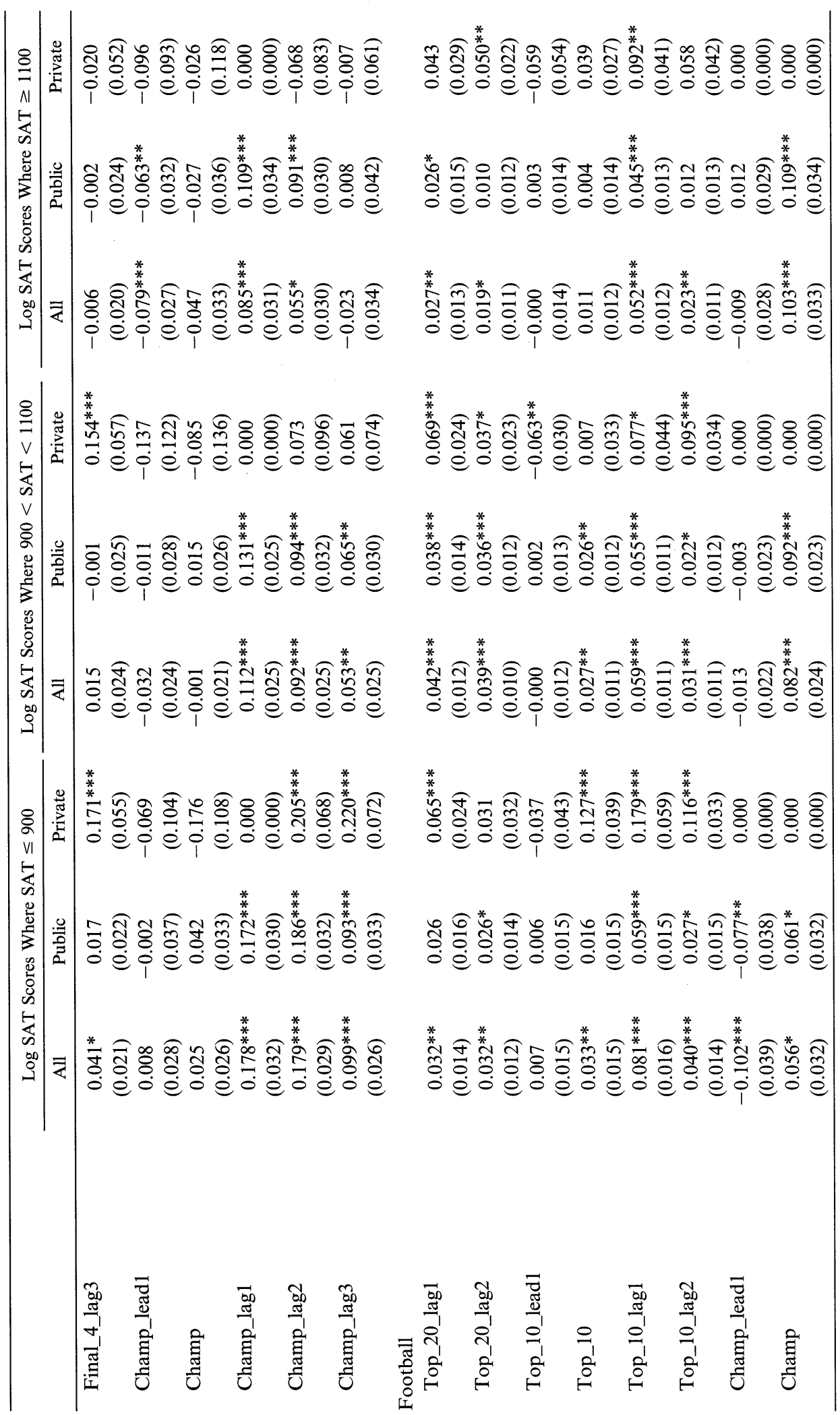




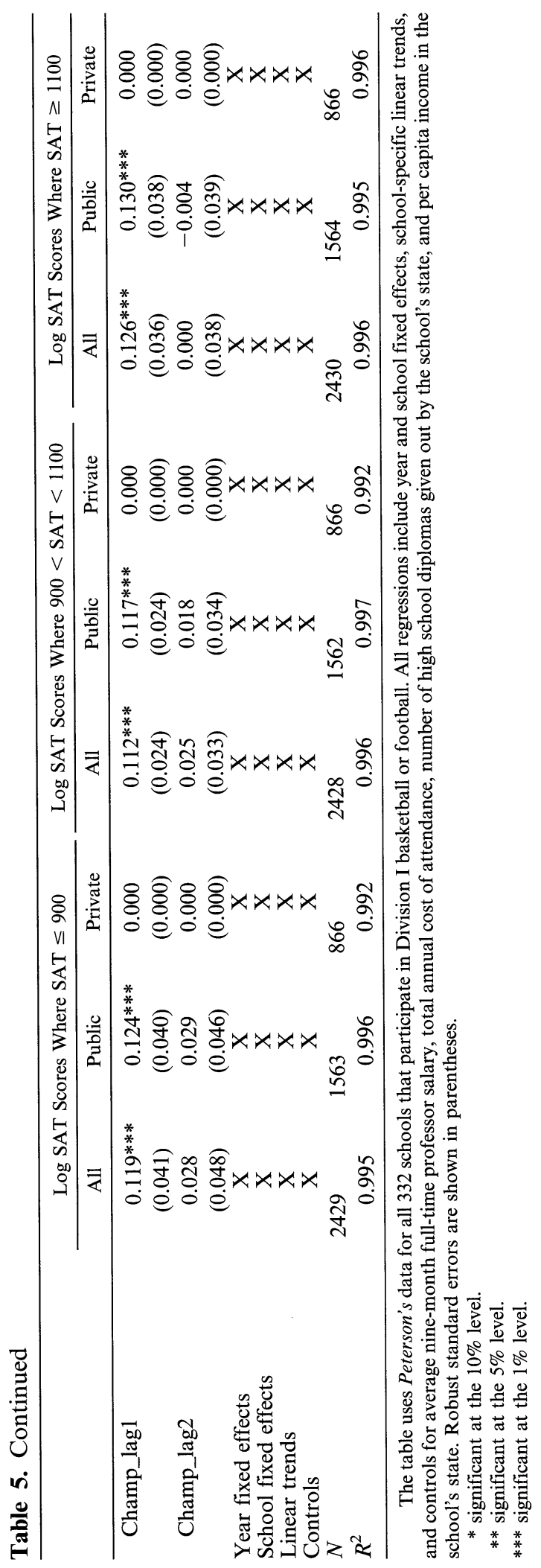


of the NCAA is beyond the scope of this study. However, the analysis presented above does provide a set of estimates about the impact of sports success on the quantity and quality of student applications at schools participating in the premier divisions of NCAA basketball and football. These estimates reflect several indirect benefits from these high-profile college sports.

Using two unique and comprehensive data sets in conjunction with an econometric design that controls for the unobservable features of schools, we find that football and basketball success increases the quantity of applications to a school after that school achieves sports success, with estimates ranging from $2 \%$ to $8 \%$ for the top 20 football schools and the top 16 basketball schools each year. ${ }^{24}$ We also provide evidence that the extra applications are composed of students with both low and high SAT scores. Additional evidence suggests that schools use these extra applications to increase both student quality and enrollment size. There is some evidence that private schools adjust tuition levels in response to receiving extra applications from basketball success.

A related paper (Pope and Pope 2007) shows that sports success has a heterogeneous impact on various subgroups of the incoming student population. For example, we found that males, blacks, and students that played sports in high school are more likely to be influenced by sports success than their peers. This finding, combined with the results of this paper, provides a much broader picture of the impact of sports success on the composition of the incoming student body. These results significantly extend the existing literature and provide important insights about the impact of sports success on college choice. Using identification strategies that exploit the temporal variation in our data sets and that control for unobserved school heterogeneity, it is increasingly clear that sports success does have an impact on the incoming freshman classes. It is also clear that this impact is often short lived, and that it differs by student type. This may reflect differences in the ability of various student subgroups to acquire quality information that would affect school choice, or it may simply reflect preferences for high-quality athletics.

Whether or not the expenditures required to receive these short-run indirect benefits promote efficiency in higher education was not determined in the present analysis. Indeed, the raw summary data in Table 2 would suggest that athletically successful schools actually saw slightly slower long-run growth in applications and enrollments. Future work directed at understanding the arms-race nature of athletics within higher education and its relation to economic efficiency would certainly be valuable. Nonetheless, the results presented in this paper should be important to college administrators. Athletics is one instrument that institutions of higher education have at their disposal that can be used to directly affect reputation and the prominence of their schools. It is hoped that these results provide information that can aid administrators in making decisions about athletic programs and help them to further understand the role of athletics within higher education.

\footnotetext{
${ }^{24}$ To put this quantity effect into perspective, the application elasticity of changes in the price of attending college found in the literature typically range from -.25 on the low end to -1.0 on the high end (see, e.g., Savoca 1990; Curs and Singell 2002). These elasticities suggest that tuition/financial aid would have to be adjusted somewhere in the range of $2-24 \%$ to obtain a similar increase in applications.
} 


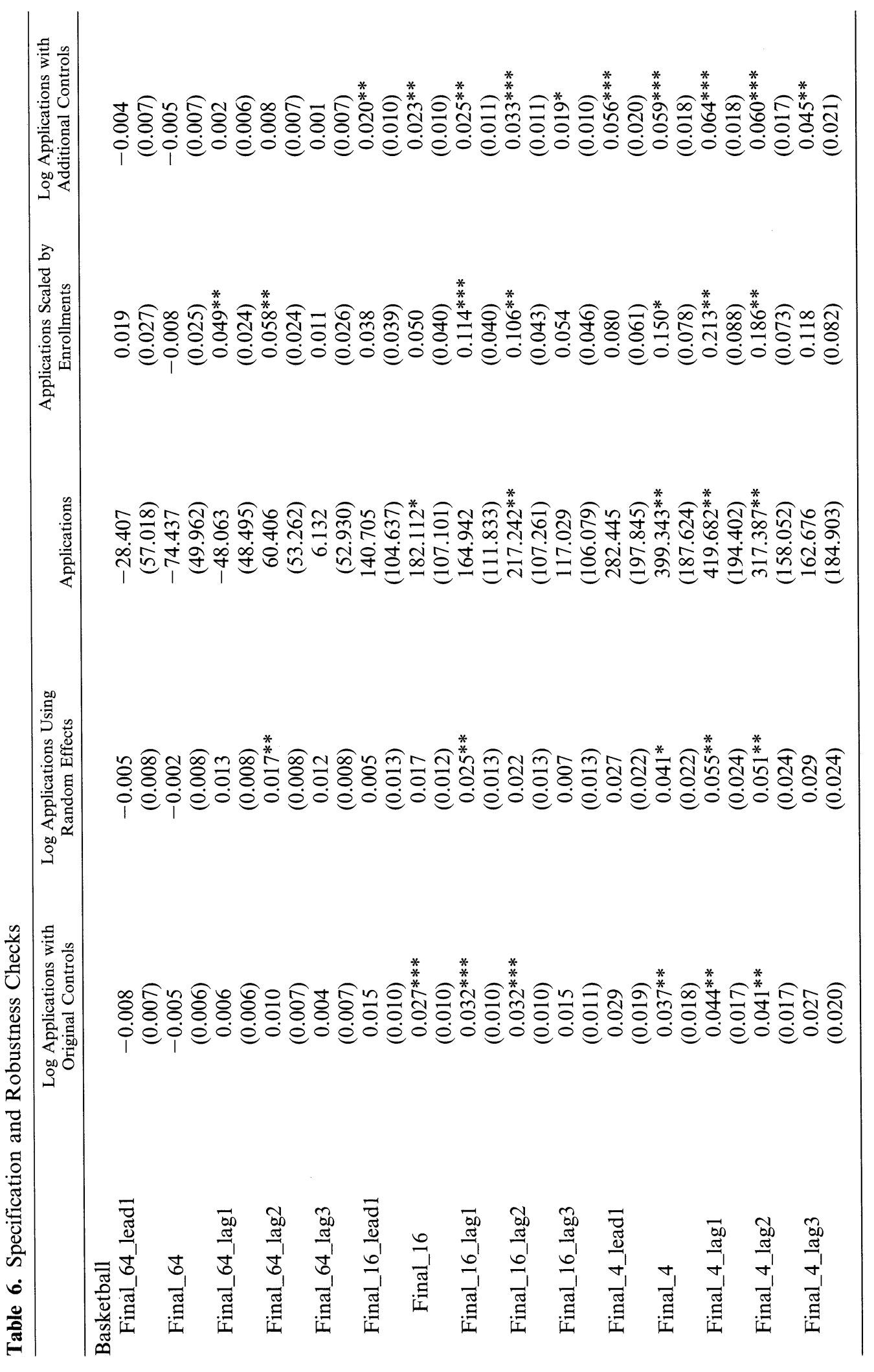




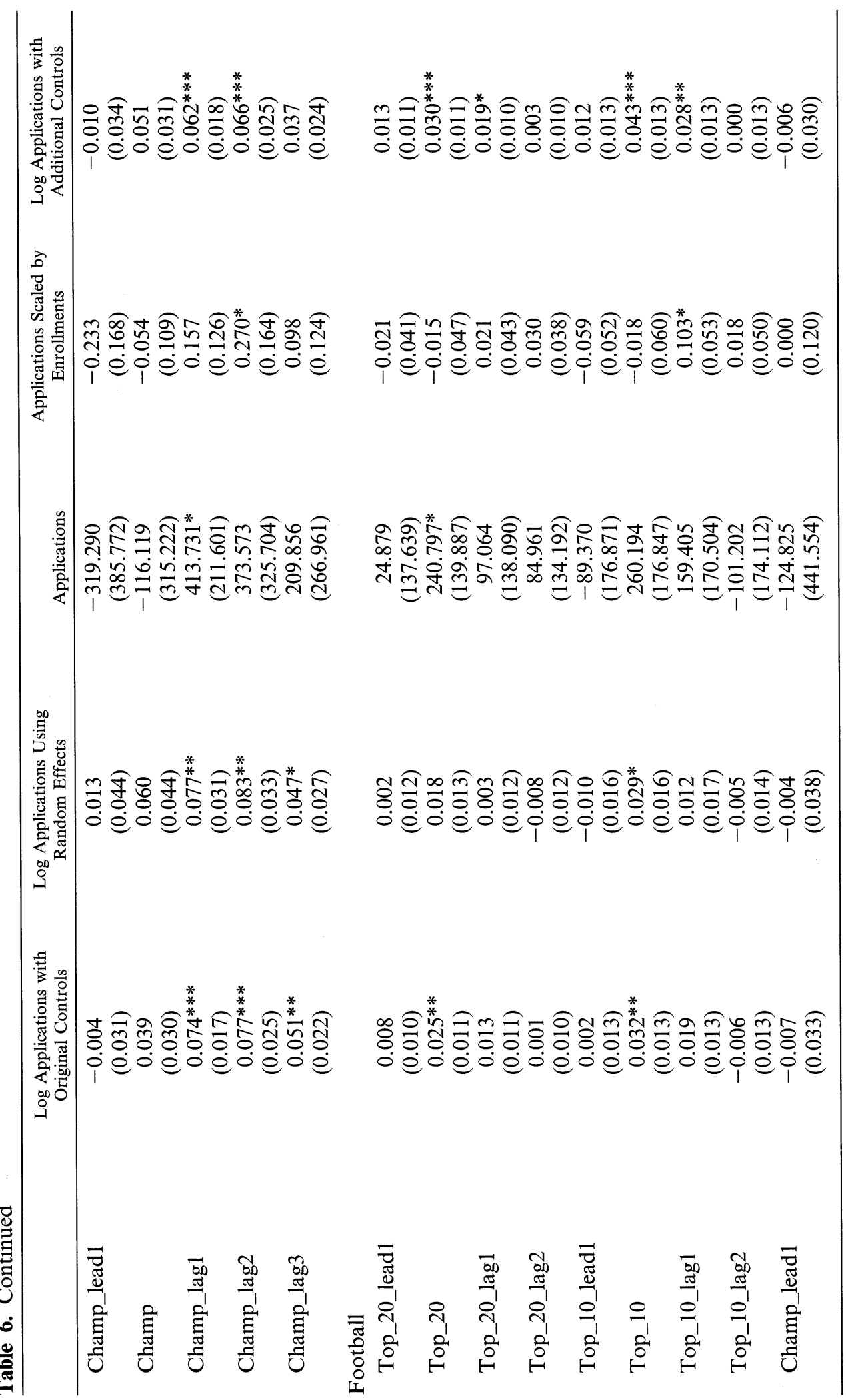




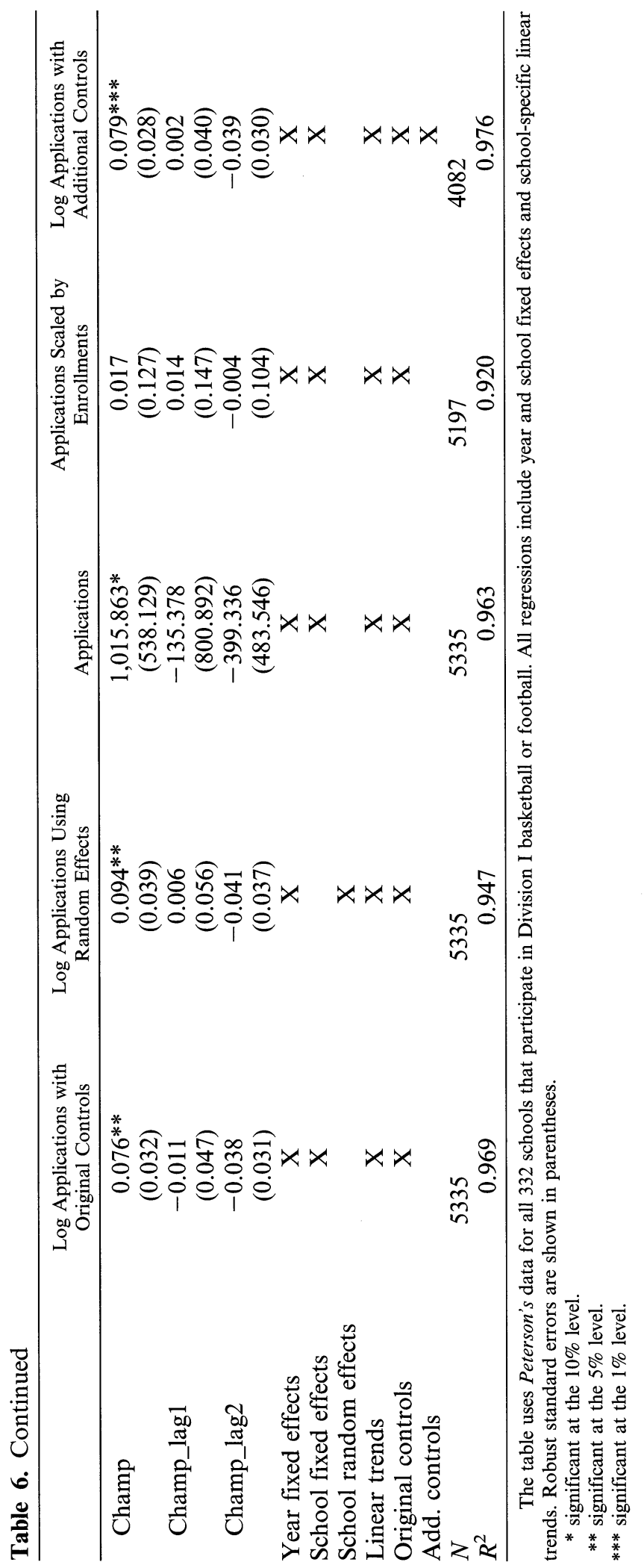




\section{References}

Avery, C., and C. Hoxby. 2004. Do and should financial aid decisions affect students' college choices? In College choices: The new economics of choosing, attending, and completing college, edited by Caroline Hoxby. Chicago: University of Chicago Press, pp. 239-299.

Bremmer, D., and R. Kesselring. 1993. The advertising effect of university athletic success-A reappraisal of the evidence. Quarterly Review of Economics and Finance 33:409-21.

Card, D., and A. Krueger. 2004. Would the elimination of affirmative action affect highly qualified minority applicants? Evidence from California and Texas. NBER Working Paper No. 10366.

Chapman, D. 1981. A model of student college choice. Journal of Higher Education 52:490-503.

Coughlin, C., and O. Erekson. 1984. An examination of contributions to support intercollegiate athletics. Southern Economic Journal 51:180-95.

Curs, B., and L. D. Singell. 2002. An analysis of the application and enrollment process for in-state and out-of-state students at a large public university. Economics of Education Review 21:111-24.

Fuller, W., C. Manski, and D. Wise. 1982. New evidence on the economic determinants of post secondary schooling choices. Journal of Human Resources 17:477-95.

Goidel, R., and J. Hamilton. 2006. Strengthening higher education through gridiron success? Public perceptions of the impact of national football championships on academic quality. Social Science Quarterly 87:851-62.

McCormick, R., and M. Tinsley. 1987. Athletics versus academics? Evidence from SAT scores. Journal of Political Economy 95:1103-16.

McEvoy, C. 2006. The impact of elite individual athletic performance on university applicants for admission in NCAA Division I-A football. The Sport Journal 9(1).

Mixon, F. 1995. Athletics versus academics? Rejoining the evidence from SAT scores. Education Economics 3:277-83.

Mixon, F., and Y. Hsing. 1994. The determinants of out-of-state enrollments in higher education: A Tobit analysis. Economics of Education Review 13:329-35.

Mixon, F., and R. Ressler. 1995. An empirical note on the impact of college athletics on tuition revenues. Applied Economics Letters 2:383-7.

Mixon, F., and L. Trevino. 2005. From kickoff to commencement: The positive role of intercollegiate athletics in higher education. Economics of Education Review 24:97-102.

Mixon, F., L. Trevino, and T. Minto. 2004. Touchdowns and test scores: Exploring the relationship between athletics and academics. Applied Economics Letters 11:421-4.

Murphy, R., and G. Trandel. 1994. The relation between a university's football record and the size of its applicant pool. Economics of Education Review 13:265-70.

Pope, D., and J. Pope. 2007. Consideration set formation in the college choice process. Unpublished paper, The Wharton School and Virginia Tech.

Savoca, E. 1990. Another look at the demand for higher education: Measuring the price sensitivity of the decision to apply to college. Economics of Education Review 9:123-34.

Siegfried, J., and M. Getz. 2006. Where do the children of professors attend college? Economics of Education Review 25:201-10.

Tucker, I. 2004. A reexamination of the effect of big-time football and basketball success on graduation rates and alumni giving rates. Economics of Education Review 23:655-61.

Tucker, I. 2005. Big-time pigskin success. Journal of Sports Economics 6:222-9.

Tucker, I., and L. Amato. 1993. Does big-time success in football or basketball affect SAT scores? Economics of Education Review 12:177-81.

Tucker, I., and L. Amato. 2006. A reinvestigation of the relationship between big-time basketball success and average SAT scores. Journal of Sports Economics 7:428-40.

Zimbalist, A. 1999. Unpaid professionals: Commercialism and conflict in big-time college sports. Princeton, NJ: Princeton University Press. 